\title{
VISUELE STEREOTIPERING VAN SPORTVROUE IN DIE SPORTMEDIA
}

\author{
Mandie BRANDT \& Adelia CARSTENS \\ Departement Geesteswetenskaplike Opvoedkunde, Fakulteit Opvoedkunde, Universiteit van \\ Pretoria, Pretoria, Republiek van Suid-Afrika
}

\begin{abstract}
Despite various attempts at achieving gender equality in sport, the media is still dominated by stereotypical representations of sportswomen. The purpose of the present research was to describe gender subjectivity and gender stereotyping in the visual portrayal of sportswomen in one of the largest South African sports magazines, and to determine the value of vector analysis as a visual-grammatical analysis instrument in identifying and opposing dominant ideologies. A literature review of published research on under-representation and stereotyping of sportswomen in the media was undertaken. The theoretical and methodological framework was Critical Discourse Analysis and Kress and Van Leeuwen's (1996; 2006) 'visual grammar', with specific emphasis on vector analysis. The types of vectors operating in visual representations and their relationship to the stereotypical constructions of sportswomen in the media were determined. Five photographs were critically analysed, one example from each stereotypical construct: 'Athletic' (the positive stereotype) as opposed to 'homosexual', 'loser', 'model' and 'sex object' (negative stereotypes) were identified. The most important conclusions are that sportswomen were predominantly stereotyped negatively in the sports magazine under scrutiny, and that vector analysis is a useful heuristic tool in identifying and confirming visual subjectivity.
\end{abstract}

Keywords: Women in sport; Critical discourse analysis; Gender stereotyping in sport; Gender inequality; Gender ideology; Vector analysis; Visual grammar.

\section{INLEIDING}

In hierdie artikel word gerapporteer oor die aard en intensiteit van gender-subjektiwiteit in die visuele afbeeldings van sportvroue oor 'n tydperk van ses jaar in een van die Suid-Afrikaanse glans-sporttydskrifte met die hoogste sirkulasiesyfers. Volblad-visuele voorstellings van sportvroue wat vanaf Januarie 2002 tot Januarie 2008 in 'n foto-rubriek in dié tydskrif gepubliseer is, is ondersoek en krities beskryf. In die analises is veral gebruik gemaak van vektoranalise as 'n tegniek wat aan die 'visuele grammatika' van Kress en Van Leeuwen $(1996 ; 2006)$ ontleen is.

\section{AGTERGROND EN RASIONAAL}

Die Vrouebeweging (1970), die instelling van Titel IX in die Verenigde State van Amerika (VSA) (Title IX, 1972), asook gendergeoriënteerde ontwikkelingsinisiatiewe het daartoe bygedra dat vroue vandag vrylik, met enkele uitsonderings, aan bykans alle sportsoorte kan 
deelneem. Gendergelykheid vir vroue in sport word ook binne die Suid-Afrikaanse konteks as een van die regering se nasionale prioriteite beskou (SRSA, 2006:3). Ten spyte van pogings tot gendergelykheid in sport word daar egter in die media steeds stereotipiese verwagtingspatrone rondom vroulike seksualiteit en vroulike optrede gestel (Houlihan, 2003:90). Stereotipering hou dikwels skadelike gevolge vir sportvroue in, professioneel, fisiek sowel as geestelik en emosioneel. Die sportmedia se dekking van vrouesport reflekteer verder selde die suksesverhale of oorwinnings van sportvroue op die sportveld deurdat daar op stereotipiese uitbeeldings gefokus word (Bishop, 2003:1,2).

Teenstrydige verwagtinge wat aan sportvroue gestel word, naamlik om 'kosmeties' fiks genoeg te wees om media-aandag te kry, en terselfdertyd fisiek in staat te wees om kompeterend deel te neem, veroorsaak dat sportvroue dikwels sielkundig knak en sodoende permanent uit sport tree. Gespierde sportvroue word ook gedurig gekonfronteer met die etiket 'lesbies' (Boutilier \& SanGiovanni, 1983:45). Sielkundige probleme onder sportvroue is nie net kommerwekkend aangesien dit fisieke skade tot gevolg het nie, maar het ook 'n direkte invloed op die toekoms van vrouesport in die algemeen. Volgens Oglesby (1978:65) het 'n sportvrou se liggaamlike selfbeeld ongetwyfeld ook 'n invloed op die keuse van 'n sportsoort, en in bykans alle gevalle dra 'n oorbeklemtoning van kosmetiese fiksheid by tot ' $\mathrm{n}$ afname in deelnemersgetalle (Coakley, 2003:249). Vanuit 'n sosiale oogpunt versterk genoemde situasie genderongelykheid, veral die mite dat sport om fisieke redes slegs vir mans geskik is.

Hoewel die afleiding gemaak kan word dat Suid-Afrikaanse sportvroue op dieselfde manier as Amerikaanse sportvroue deur stereotiperende mediadekking geraak word, is daar klaarblyklik nog geen empiriese studies oor die visuele of verbale diskoers ten opsigte van sportvroue in die Suid-Afrikaanse media gepubliseer nie. Die geskiedenis van vrouesport in Suid-Afrika is ook nog nie grondig gedokumenteer nie (Hargreaves, 1997:192). Verder berus uitsprake oor genderrolstereotipering op die subjektiewe oordeel van individue, en is dit nie maklik om te bewys dat die voorstelling van veral sportvroue deur die media teenstrydig is met die gewenste uitbeelding nie, naamlik as kompeterende en/of professionele sportlui.

In hierdie artikel word gepoog om 'n bydrae te lewer tot die vul van hierdie navorsingsleemte deur die aanwesigheid van stereotipering in die Suid-Afrikaanse glans-sporttydskrif met die tweede grootste sirkulasiesyfer, uit te lig en te belig aan die hand van kritiese analises en om die heuristiese waarde van vektoranalise as 'n visuele analise-instrument te toon.

Eerstens word 'n oorsig gegee van gepubliseerde empiriese studies oor mediadekking van mans en vroue in die tydskrif Sports Illustrated (VSA-uitgawe), en leemtes in hierdie studies word uitgewys. Dit word gevolg deur 'n beskrywing van die metodologie wat gevolg is vir die navorsing waaroor in hierdie artikel gerapporteer word, en 'n bespreking van die bevindinge. Die artikel word afgesluit met 'n gevolgtrekking oor die aard van die visuele stereotipering van sportvroue in die Suid-Afrikaanse ekwivalent van laasgenoemde tydskrif, en die moontlike rol wat elemente van 'n visuele grammatika in die identifisering daarvan kan speel. 


\section{LITERATUUROORSIG: GENDERONGELYKHEID IN SPORTS ILLUSTRATED (VSA-UITGAWE)}

Eerstens is die gebrekkige verteenwoordiging van sportvroue in Sports Illustrated kommerwekkend. Reid en Soley (1979) se inhoudsanalise van die uitbeelding van sportvroue in Sports Illustrated tussen 1956 en 1976 het bevind dat sportvroue persentasiegewys slegs $3.2 \%$ mediablootstelling kry, teenoor $6.9 \%$ tydskrifspasie wat aan sportmans gewy word (Reid \& Soley, 1979:4). Bishop (2003:192) se analise van Sports Illustrated gedurende die 1980s, vier jaar na die studie van Reid en Soley, het bevind dat daar geen merkwaardige toename in die aantal artikels oor vrouesport was nie en dat slegs drie van die artikels in die datakorpus sportvroue se suksesverhale op die sportveld beskryf het. Verder is ook bevind dat sportvroue in sekondêre rolle teenoor sportmans uitgebeeld word (Bishop, 2003:192).

Boutilier en SanGiovanni (1983:209) het die visuele gelykberegtiging van mans en vroue in Sports Illustrated ondersoek, en het aangetoon dat sportvroue minder as 5\% publisiteit deur middel van foto's geniet het in die uitgawes wat tussen 1954 en 1978 verskyn het. Fink en Kensicki (2002) rapporteer dat die analise van die visuele diskoers op voorblaaie van Sports Illustrated oor 'n tydperk van drie dekades (1957-1989) bevind het dat sportvroue steeds minder mediablootstelling geniet en meer stereotipies op sporttydskrifte se voorblaaie as sportmans uitgebeeld word. Volgens Kane (1996:7) het hierdie patrone van mediablootstelling nie veel verander sedert die genoemde navorsing nie, en verwys spesifiek na 'n studie van 1991 wat bevind het dat 91\% van die inhoud van Sports Illustrated sportmans en hulle prestasies verteenwoordig. 'n Soortgelyke studie wat 1105 artikels en 1745 foto's in Sports Illustrated tussen 1997 en 1999 ondersoek het, het aangetoon dat sportvroue steeds onderverteenwoordig is en in tradisionele rolle in die nie-sportkonteks uitgebeeld word (Fink $\&$ Kensicki, 2002). Die gebrekkige verteenwoordiging van sportvroue in die media is ook nie slegs beperk tot volwasse sportvroue nie, en duidelike genderfrekwensie-uitvalle is ook in die weergawes van Sports Illustrated for Kids (VSA-uitgawe) aanwesig. Die ratio van visuele beelde (foto's) in 'n ondersoek van Duncan en Sayaovong (1990) was 62\% seuns teenoor 28\% meisies.

Die wanbalans in die mediadekking van sportmans en -vroue kan moontlik geregverdig word deur die argument dat Sports Illustrated se grootste lesersaanhang uit mans bestaan. Bishop (2003:192) redeneer egter dat Sports Illustrated een van die VSA se gewildste sporttydskrifte is, en ook so bemark word (Bishop, 2003:192), sonder verwysing na een van die geslagte. Die tydskrif het derhalwe 'n etiese verantwoordelikheid om gelykwaardige dekking aan vrouesowel as aan mansport te verleen. Die Suid-Afrikaanse situasie is hiermee vergelykbaar. Sirkulasiesyfers wat deur Media 24 versprei is, het aangedui dat Sports Illustrated se SuidAfrikaanse eweknie die tweede hoogste sirkulasiesyfer naas die sokkertydskrif Kick Off SA, sedert sy debuut in 1986, handhaaf (Naspers, 2006:1). In die tweede instansie is vrouesport meer populêr as ooit, op professionele sowel as op tersiêre vlak (Bishop, 2003:192). Bogenoemde studies toon duidelik aan dat sportmans en -vroue, spesifiek in die VSA, nie gelyke beregtiging geniet in terme van mediadekking in een van die algemene sporttydskrifte met die hoogste sirkulasiesyfers, te wete Sports Illustrated, nie.

Naas die kwessie van verteenwoordiging het 'n aantal navorsers ook die stereotipiese uitbeelding van sportvroue op verbale en visuele vlak in Sports Illustrated ondersoek. In die 
algemeen is bevind dat sportvroue steeds volgens stereotipiese verwagtingspatrone uitgebeeld word: 'n bepaalde fisieke profiel ('n perfekte bolyf, heupe, haarstyl, gelaatstrekke, plankdun) sowel as 'n bepaalde sosiale profiel (vroulike optrede, nie-kontroversiële gedrag, vroulike kleredrag) (Boutilier \& SanGiovanni, 1983:21,45; Coakley, 2003:248). Gespierde sportvroue word verder met die etiket 'lesbies' (Boutilier \& SanGiovanni, 1983:45) gekonfronteer. Verskeie studies toon dat bepaalde sporttipes binne die konteks van vrouesport meer mediablootstelling as ander kry. Daar word in die verband na 'geslagsgewenste' en 'geslagsongewenste' sportsoorte verwys. Mary Jo Kane, bekende navorser en direkteur van die Tucker-sentrum vir navorsing oor vrouesport in die VSA, is van mening dat sportvroue steeds nie werklikheidsgetrou uitgebeeld word nie. Kane doen 'n beroep op die media om vroulike 'skoonheid' met 'fisieke krag' te kombineer in 'n poging om die realiteit van sportvroue in die media te kommunikeer (Women's Sports Foundation, 2010). Sy eis dat sportvroue so uitgebeeld word dat hul vaardighede as sportvroue ten toon gestel word, en nie as modelle wat tydskrifte verkoop nie. Seksistiese beelde word egter steeds gebruik om vrouesport te bevorder deur hulle as seksobjekte eerder as sportvroue voor te stel (Women's Sports Foundation, 2010).

Die meeste studies oor stereotipering van sportvroue in die media skiet daarin tekort dat hulle grootliks impressionisties is, en dat die uitbeelding van sportvroue in sporttydskrifte nie op 'n sistematiese wyse ondersoek en beskryf word nie. Hoewel die datakorpus vir die navorsing waaroor in hierdie artikel gerapporteer word, relatief klein is, word gepoog om die visuele diskoers oor sportvroue in die Suid-Afrikaanse ekwivalent van Sports Illustrated sistematies te beskryf deur van 'n visueel-grammatiese metode wat bekend staan as vektoranalise gebruik te maak.

\section{TEORETIESE ONDERBOU}

Kritiese Diskoersanalise (KDA), wat bekend geword het deur die werk van taalkundiges soos Fairclough (2001, 2003, 2004), Wodak en Meyer (2001), Wodak (2006), Van Dijk (1993, 1997a, 1997b, 2004, 2005), het as teoreties-filosofiese raamwerk vir die navorsing gedien. KDA het veral ten doel om die wyse te belig waarop diskoers sosiale entiteite (insluitende sportvroue) konstrueer. Die kritiese perspektief van KDA is dus gerig op die ontmaskering van diskursiewe magsmisbruik wat sosiale ongelykheid bevorder. KDA het dié tekortkoming dat dit nie oor 'n model of raamwerk beskik waarvolgens diskoerse op mikrovlak ontleed kan word nie. Vir dié doel is daar veral sterk op Halliday se Sistemies Funksionele Grammatika gesteun (Halliday, 1994; Halliday \& Mathiessen, 2004). Met die toenemende klem op die multimodaliteit van diskoerse het 'n behoefte ontstaan aan 'n grammatika wat ook ander semiotiese sisteme insluit.

Kress en Van Leeuwen het hierdie leemte in die middel negentigerjare waargeneem en die eerste redelik algemeen aanvaarde 'visuele grammatika' opgestel, gegrond op Sistemies Funksionele Grammatika (Kress \& Van Leeuwen, 1996). Die outeurs verdeel alle visuele afbeeldings in twee kategorieë, naamlik 'narratief' en 'konseptueel'. Narratiewe afbeeldings bevat 'n aksiekomponent en konseptuele afbeeldings is hoofsaaklik staties en tydloos. Die foto's wat in sportverslaggewing gebruik word, behoort tipies tot die narratiewe kategorie deurdat hulle beskryf kan word as "unfolding actions and events, processes of change, and transitory spatial arrangements" (Kress \& Van Leeuwen, 2006:59). Wanneer 'n objek of 
entiteit as die aktiewe deelnemer in die visuele afbeelding beskou word, word die betrokke persoon die 'doener' (actor) genoem. Die verbindingslyn, denkbeeldig of werklik, word 'n vektor genoem. Die entiteit waarmee die doener wisselwerking uitoefen, word die 'doel' genoem, en hierdie is die entiteit waarmee die doener se vektore verbind word om 'n soort aksie of interaksie te vergestalt. Vektore word gewoonlik gevorm deur uitgebeelde elemente in die foto met mekaar, of met elemente in 'n ander afbeelding, deur middel van 'n lyn wat dikwels 'n sterk, diagonale lyn is te verbind (Kress \& Van Leeuwen, 1996:47). Die lyne kan tussen liggaamsdele strek of tussen liggaamsdele en statiese objekte.

Kress en Van Leeuwen (1996; 2006) onderskei drie tipes vektore, naamlik, aksievektore, reaksievektore en statiese vektore. Daarbenewens onderskei die navorsers ook tussen sensuele en emosionele vektore, wat tipes reaksievektore is en wat staties of nie-staties mag wees, maar wat na sensuele aspekte verwys. Die vektorlyn wat gevorm word, stel dus die sportvrou op so 'n manier aan die leser bekend dat die fokus op die seksuele en sensuele val. Vervolgens word 'n oorsig gegee oor die onderskeie tipes vektore wat vir die analise van sportfoto's onderskei is.

- Aksievektore is vektore wat gebruik word om die sportvrou se liggaam vir die kyker in 'n spesifieke sporthouding of -posisie te plaas. Die gevolg is die beklemtoning van die sportaksie, en die fokus word op sportapparaat of -toerusting gestel. Hierdie vektore is dus in die konteks van hierdie studie 'positief' van aard in die sin dat hulle die sportvrou positief stereotipeer, deur haar as 'atleties' uit te beeld.

- Reaksievektore is die vektore wat gevorm word op die ooglyn, deur die rigting van die starende blik ('gaze'), van een of meer deelnemers (verteenwoordigers). Die 'reaktor' is die persoon wat self verantwoordelik is vir die 'kyk' (Cross, 2006:176). Die fenomeen mag ook deur 'n ander deelnemer of deur die deelnemer na wie die 'reaktor' kyk, gevorm word. Die starende blik het tot gevolg dat die sportvrou op grond van haar 'gesigsuitdrukking' as 'model' voorgestel word.

- Statiese vektore is horisontale of vertikale lyne, dus nie skuins lyne nie, wat die subjek as staties of passief posisioneer. Sportaksie word dus in die proses onderdruk. Die sportvrou word so tipies as 'model' of 'verloorder' uitgebeeld. Uiteraard kan meer as een tipe vektor in dieselfde visuele voorbeeld voorkom en sodoende twee of meer van bogenoemde vektor-kategorieë kombineer.

- Sensuele aksievektore is 'n kategorie wat op beide die sensuele en sportaksie van die sportvrou fokus en die sportvrou op dié wyse as 'homoseksueel' posisioneer.

- Sensuele en emosionele vektore is vektore wat, deur die fokus op sensuele en emosionele komponente in die visuele uitbeelding, die sportaksie onderdruk en so emosie oorbeklemtoon en die sportvrou gevolglik as 'verloorder' uitbeeld.

Die bespreekte vektore is in Tabel 1 volgens hulle vorm gekategoriseer, asook die belangrikste dimensies of konstrukte van stereotipering wat hulle tot gevolg het, naamlik die uitbeelding van die sportvrou as homoseksueel, model, verloorder, seksobjek en atleet. Hierdie dimensies is gekoppel aan visueel uitbeeldbare eienskappe van sportvroue (konstrukeienskappe), byvoorbeeld 'liggaamshouding', '-bou', 'kleredrag' en 'gesigsuitdrukking'. 
TABEL 1: TIPES VEKTORE

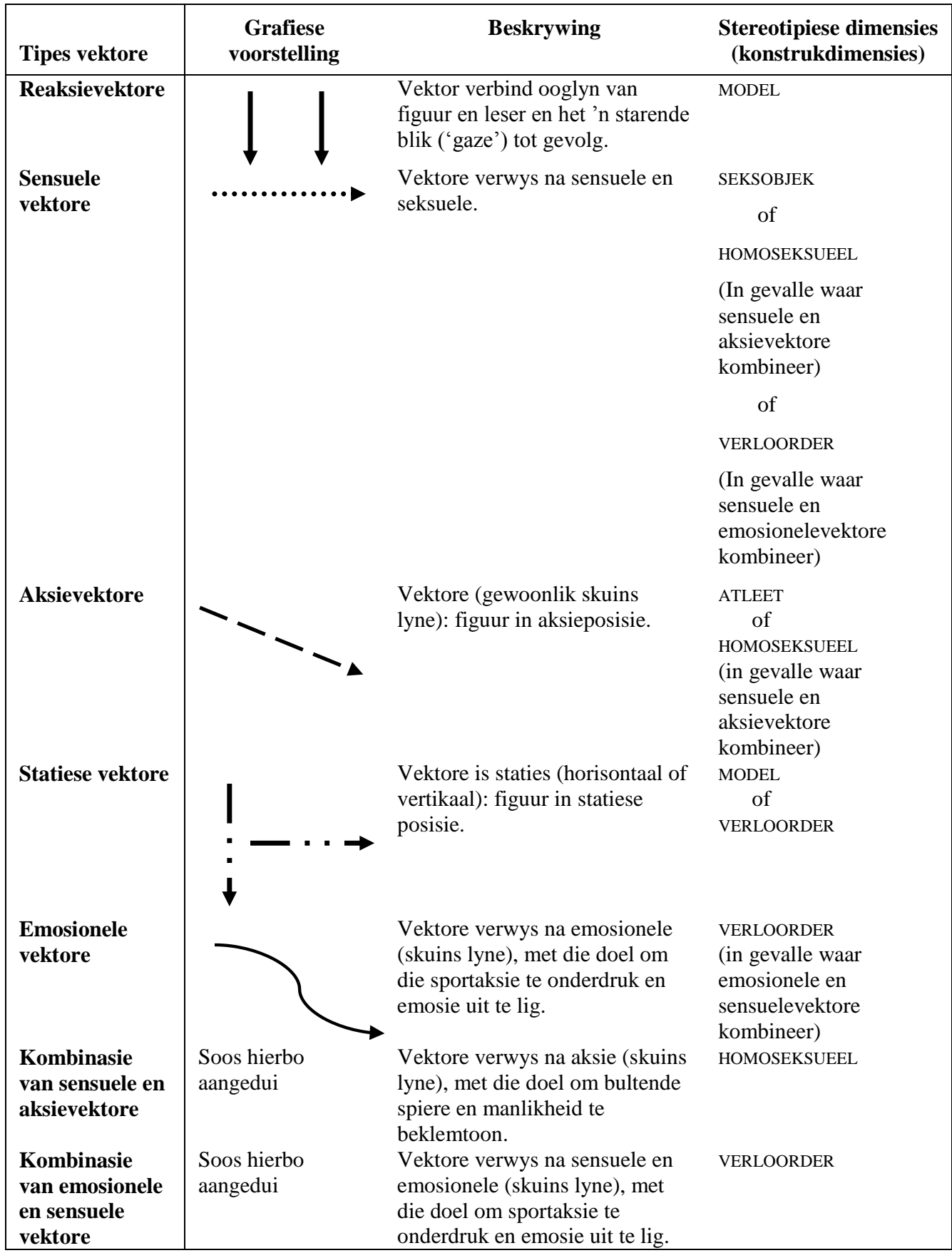


Volgens Kress en Van Leeuwen (1996) gee vektore tot 'visuele mediëring' aanleiding. Laasgenoemde behels die subjektiewe samestelling van visueel-semiotiese elemente deur die media. Die keuses wat die fotograaf as visuele skepper ('mediator') uitoefen met betrekking tot elemente van visuele grammatika, lei dikwels tot gendersubjektiwiteit (McGinnis et al. 2003:11).

\section{KRITIESE ANALISES}

\section{Metode}

Eers is die vektore visueel op elke foto aangebring met behulp van vektorpyle, en daarna is die korpus van dertien foto's krities ontleed volgens die tipologie. Die tipes vektore (soos uiteengesit in Tabel 1) is geïdentifiseer op grond van pertinente lyne wat deur die sportvroue se 'liggaamshouding', '-bou', 'kleredrag' en 'gesigsuitdrukking' gevorm word, en vestig die leser se verbeelding en aandag op die simboliese waarde en 'betekenis agter die lyn' (Kress \& Van Leeuwen, 1996:70). Die stereotipiese konstrukdimensies is vervolgens bepaal. Vir die doel van die artikel is die gesigte op die foto's verdof ten einde anonimiteit te verseker. Kopiereg is bekom deur die aankoop van die betrokke foto's via Gallo Images.

\section{Analise van vyf foto's}

Een foto wat verteenwoordigend is van elkeen van die vyf konstrukdimensies (homoseksueel, model, verloorder, seksobjek, atleet) is vir bespreking in hierdie artikel geselekteer. Slegs die konstrukdimensie 'atleet', verteenwoordig positiewe stereotipering (gewenste uitbeelding), terwyl al die ander dimensies die sportvrou op nie-gewenste wyses uitbeeld. In Figuur 1 word die sportvrou, gegrond op die vektoranalise, as 'homoseksueel' uitgebeeld.

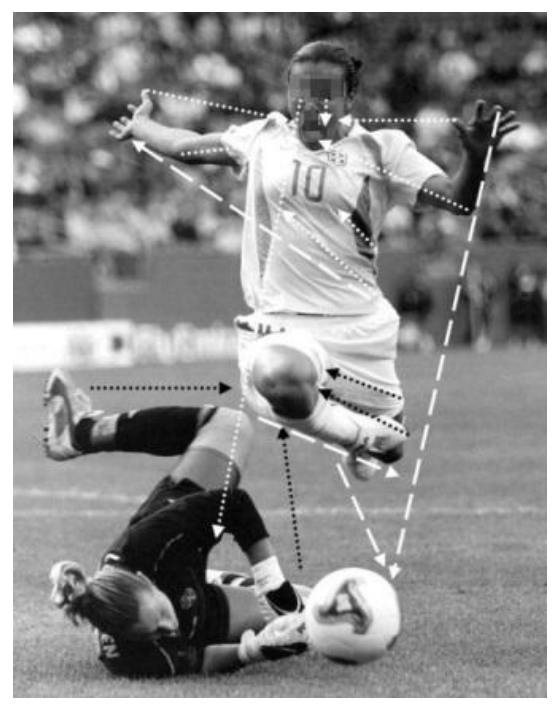

FIGUUR 1: FOTO 1 MET VEKTOR-ANALISE

(SA Sports Illustrated, 2004a) 
In die uitbeelding van die voetbalspeler (sportvrou met nommer 10 op haar hemp), is daar 'n aantal sensuele aksievektore aanwesig, wat veral 'liggaamsbou' en '-houding' beklemtoon. Die stereotipiese konstrukdimensie wat hier ter sprake is, is 'homoseksueel' (Tabel 1). Die sensuele vektore verwys na 'n oormatig gespierde, onvroulike, aggressiewe en arrogante 'liggaamshouding'. Die oormatig gespierde 'liggaamsbou' word beklemtoon deur vektore wat verwys na die bultende arm- en beenspiere en die onvroulike 'liggaamshouding' deur arms wat oopgesprei is en die bors wat uitgestoot is. Die vektore wat die gespanne mond- en gesigspiere beklemtoon, beklemtoon die aggressie van die sportvrou en die gespanne nek-, gesig- en armspiere en uitgestote bors wat deur die vektore uitgelig word, beklemtoon die arrogante 'liggaamhouding'. Die aksievektore plaas klem op sportaksie en daardeur word die aktiewe 'liggaamshouding' uitgelig.

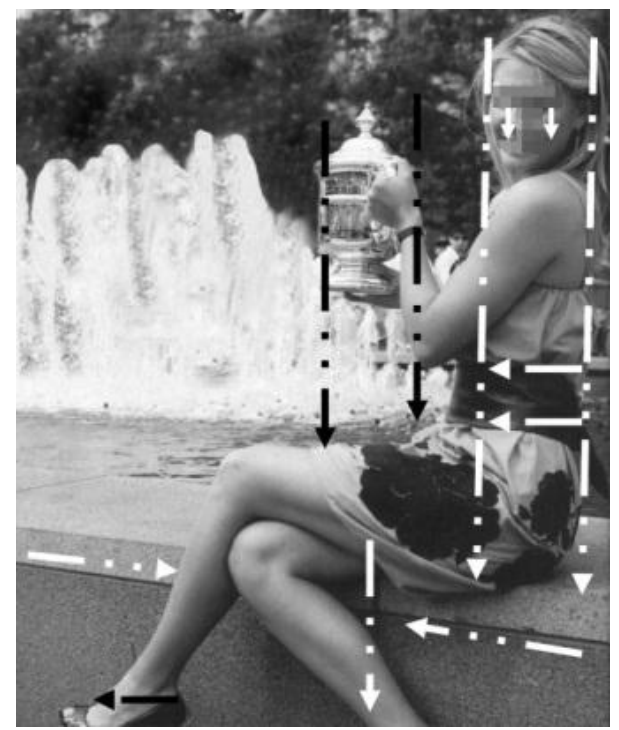

\section{FIGUUR 2: FOTO 9 MET VEKTOR-ANALISE}

(SA Sports Illustrated, 2004b)

Foto 9 (Figuur 2) uit die korpus is 'n voorbeeld van die negatiewe stereotipering van die sportvrou as 'model'. In die uitbeelding (Figuur 2), speel die reaksie- en statiese vektore 'n bepalende rol. Die reaksievektore veroorsaak 'n starende blik vanaf die sportvrou se ooglyn na die leser, wat haar verleidelikheid beklemtoon. Die nie-sportiewe 'kleredrag' word deur die statiese vektore, wat na die modeskoene verwys, beklemtoon. Die gedraaide skouer en die vektore wat na die bene en skoene verwys, versterk die verleidelike 'liggaamshouding'. Die statiese vektore beklemtoon verder die loopplankmodel-'liggaamsbou' en word ondersteun deurdat sportaksie (aksievektore) ontbreek.

Foto 4 kan beskou word as 'n voorbeeld van die uitbeelding van die sportvrou as 'verloorder', op grond van die vektoranalise, soos aangedui in onderstaande voorbeeld (Figuur 3). 


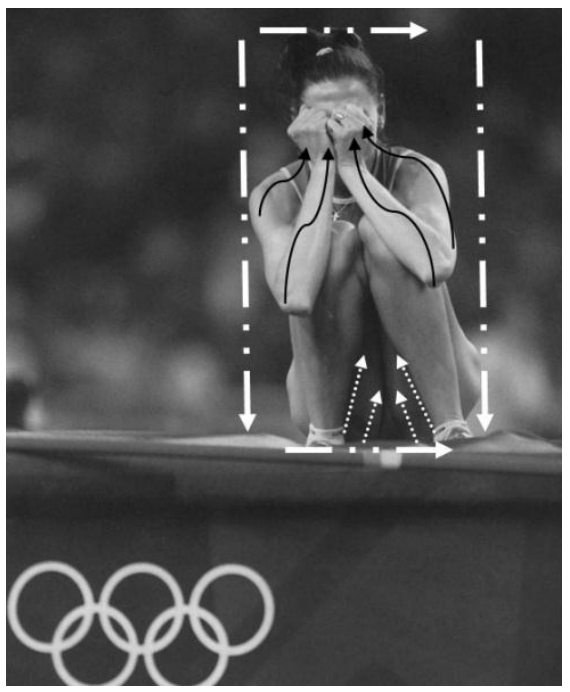

\section{FIGUUR 3: FOTO 4 MET VEKTOR-ANALISE}

(SA Sports Illustrated, 2004c)

In hierdie uitbeelding (Figuur 3) is daar 'n aantal sensuele, emosionele en statiese vektore teenwoordig, wat bydra tot die uitbeelding van die sportvrou as 'verloorder'. Die sensuele en emosionele vektore beklemtoon die sportvrou se 'liggaamsbou', '-houding', en emosionele aard, wat teenstrydig is met 'n sportiewe uitbeelding. Die statiese vektore beklemtoon die passiewe 'liggaamshouding' en gebrek aan sportaksie.

Die sportvrou word ook dikwels as 'seksobjek' uitgebeeld. Foto 12 is deur die navorser geïdentifiseer as 'n voorbeeld van die uitbeelding van die sportvrou as seksobjek, gebaseer op die vektoranalise (Figuur 4).

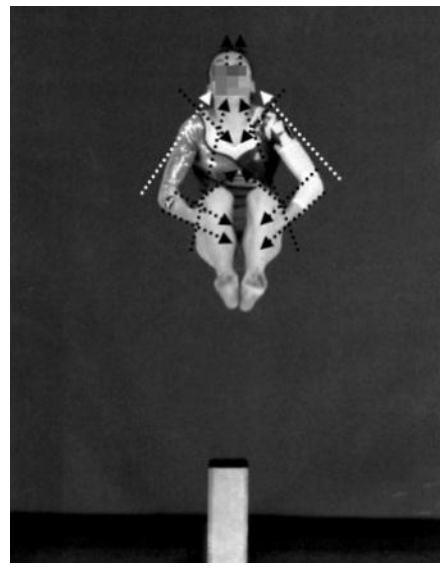

FIGUUR 4: FOTO 12 MET VEKTOR-ANALISE

(SA Sports Illustrated, 2008) 
In Figuur 4 word die sportvrou, deur die aanwesigheid van 'n groot aantal sensuele vektore as seksobjek voorgestel. Die vektore plaas klem op haar 'liggaamshouding' en 'gesigsuitdrukking', wat die konstrukdimensie ondersteun. Die sensuele vektore beklemtoon die nie-doelgerigte 'gesigsuitdrukking', deurdat die vektore die sportaksie en -toerusting onderspeel en die fokus dus nie-gedefinieerd voorkom. Die sportvrou se oop mond en ooglyn wat verwyder is van die sportaksie, gee aanleiding tot die verleidelike 'gesigsuitdrukking' en die vektore wat die sensuele en seksuele beklemtoon, ondersteun die verleidelike 'liggaamshouding'.

Foto 2 uit die datakorpus kan as voorbeeld gebruik word om die uitbeelding van die sportvrou as 'atleties' te illustreer. Hierdie konstrukdimensie word as prototipies vir die uitbeelding van sportvroue in die media beskou (Figuur 5).

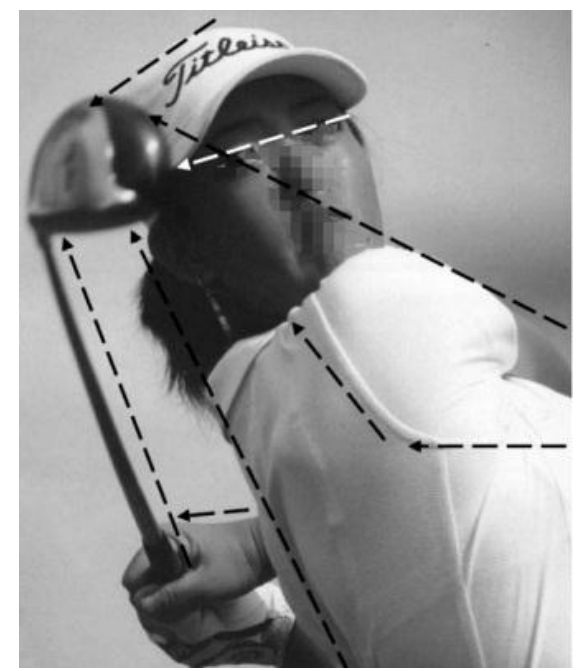

\section{FIGUUR 5: FOTO 2 MET VEKTOR-ANALISE}

(SA Sports Illustrated, 2004b)

In Figuur 5 is daar heelwat aksievektore teenwoordig. Die prototipiese konstrukdimensie 'atleties' word gevolglik daardeur versterk. Die aksievektore verwys na 'n atletiese 'liggaamsbou', sportiewe 'kleredrag', vroulike 'liggaamshouding' en gedetermineerde 'gesigsuitdrukking'. Die aktiewe, atletiese 'liggaamsbou' word beklemtoon deur die klem na die sportaksie te verskuif. Alle vektore wys na die gholfstok (sportapparaat). Die 'kleredrag' word nie oor- of onderbeklemtoon nie en die tipe 'liggaamsbou' word onderspeel, deurdat klem op die sportaksie val.

\section{Opsomming van bevindinge}

Volgens vektoranalises van die hele datakorpus van 13 foto's is vyf geïdentifiseer as prototipiese uitbeeldings van sportvroue. Hierdie foto's word as positief stereotiperend beskou en is onder die konstrukdimensie atleties gekategoriseer. Die foto's word visueel in Figuur 6 opgesom. 


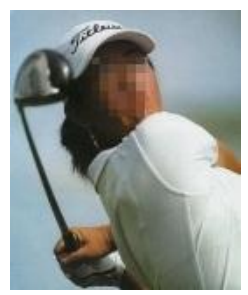

Foto 2

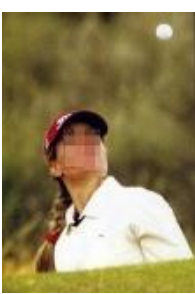

Foto 7

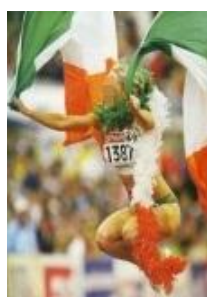

Foto 8

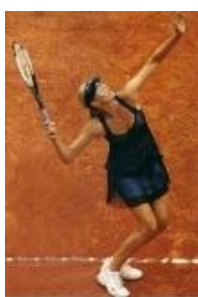

Foto 10

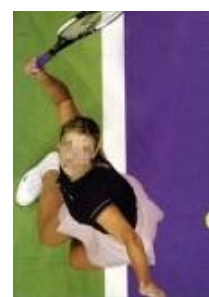

Foto 13

FIGUUR 6: FOTO'S VERTEENWOORDIG KONSTRUKDIMENSIE 'ATLETIES'

Agt van die 13 foto's is op grond van die vektoranalises as negatief stereotiperend geklassifiseer, en dus as nie-gewenste uitbeeldings van sportvroue. Hierdie foto's is onder die konstrukdimensies homoseksueel, verloorder, model en seksobjek gekategoriseer. Die foto's word visueel in Figure 7-10 opgesom.

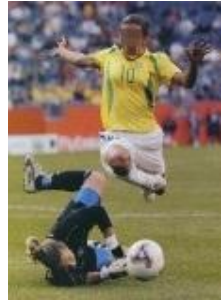

Foto 1

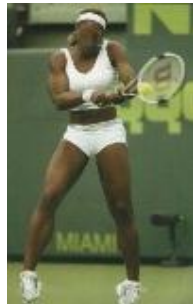

Foto 3

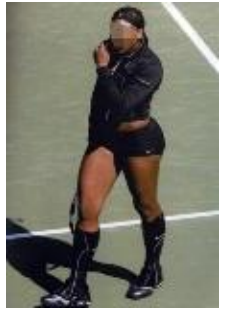

Foto 5

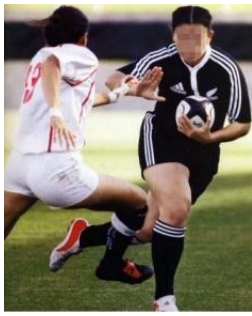

Foto 6

FIGUUR 7: FOTO'S VERTEENWOORDIG KONSTRUKDIMENSIE 'HOMOSEKSUEEL'

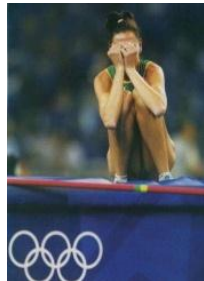

Foto 4

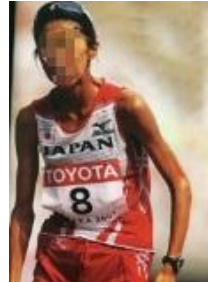

Foto 11

FIGUUR 8: FOTO'S VERTEENWOORDIG KONSTRUKDIMENSIE 'VERLOORDER'

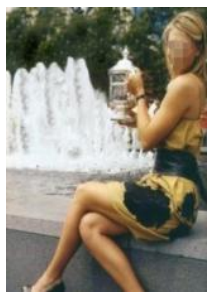

Foto 9

FIGUUR 9: FOTO VERTEENWOORDIG KONSTRUKDIMENSIE 'MODEL' 


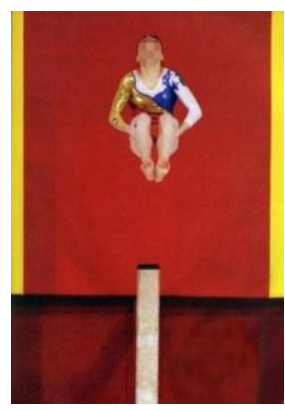

Foto 12

FIGUUR 10: FOTO VERTEENWOORDIG KONSTRUKDIMENSIE 'SEKSOBJEK'

\section{GEVOLGTREKKINGS EN TOEKOMSTIGE NAVORSING}

Die belangrikste gevolgtrekkings wat uit hierdie studie gemaak kan word, is dat sportvroue oorwegend negatief in gestereotipeer word in die glans-sporttydskrif met die tweede grootste sirkulasiesyfer in Suid-Afrika, en dat vektoranalise 'n nuttige heuristiese middel is om visuele subjektiwiteit te identifiseer en te bevestig in die uitbeelding van sportvroue in die media. Met die oog op toekomstige navorsing word daar aanbeveel dat die visuele grammatika van Kress en Van Leeuwen (1996; 2006) meer omvattend en uitgebreid toegepas word. In hierdie studie het die diskoersanalise hoofsaaklik van vektoranalise gebruik gemaak om die stereotipiese konstrukdimensies en eienskappe van visuele subjektiwiteit te identifiseer. Ander visueel-grammatiese elemente, byvoorbeeld perspektief, aansig, voor- en agtergrondprominensie, figuurkomposisie en uitleg, behoort in toekomstige studies in kritiese analises gebruik te word, eerstens om 'n meer genuanseerde beskrywing van visuele subjektiwiteit te gee, en tweedens om te bepaal of hierdie visuele elemente vektoranalise ondersteun, aanvul of selfs teenstrydige resultate oplewer.

\section{SUMMARY}

\section{Visual stereotyping of sportswomen in the sports media}

This article reports on the nature and extent of gender subjectivity in the visual representation of sportswomen in the glossy sports magazine with the second largest readership in South Africa. Secondly, it aims at determining the value of visual-grammatical analysis in identifying and opposing dominant ideologies.

Despite institutional and public attempts at achieving gender equality in sport stereotypical representation of sportswomen in the media is still an everyday occurrence. Instead of representing sportswomen as physically and mentally strong professionals, they are habitually portrayed as catwalk/photographic models, sex objects, losers or lesbians. These representations are probably fuelled by stereotypical expectations regarding female sexuality and feminine behaviour. Apart from the fact that sportswomen do not approve of the way they are regularly represented, it is also a well-documented fact that stereotyping has a number of negative effects on sportswomen, professionally and physically, as well as mentally and emotionally. Contradictory expectations, for example, to be 'cosmetically' fit for 
media attention, yet physically fit to compete professionally, often result in psychological breakdown and may even cause permanent resignation from sport.

All the full-page visual representations of sportswomen that appeared in the photo section of the particular magazine between January 2002 and January 2008 were critically analysed. An overview is given of published research on under-representation and stereotyping of sportswomen in the media, with specific reference to the United States counterpart, Sports Illustrated. A research deficiency was identified, namely a lack of systematic empirical studies on visual stereotyping of sportswomen in the sport media, particularly in the South African sport media. The theoretical and methodological framework that underpinned the study was Critical Discourse Analysis and Kress and Van Leeuwen's (1996) so-called 'visual grammar', which is a 'translation' of Hallidayan Systemic Functional Grammar. Critical Discourse Analysis served as the analytical and philosophical framework, while vector analysis was selected as the analytical tool. Five types of vectors were distinguished: static vectors, action vectors, reaction vectors, sensual vectors and emotional vectors. In the article five photographs from a total corpus of 13 were critically analysed, one example from each stereotypical construct. The critical analyses of the selected photographs culminated in the findings regarding all 13 photographs comprising the corpus.

The main finding is that five $(38.5 \%)$ of the 13 photographs comprising the corpus portray sportswomen in a positive or desirable way, namely as 'athletic', while the remaining eight photographs (61.5\%) portray the sportswomen in stereotypical ways, that is as 'homosexual', 'loser', 'model' and 'sex object'. The most important conclusions derived from this study were firstly, that the visual portrayal of sportswomen in the South African glossy sports magazine with the second largest readership confirm and perpetuate stereotypes that increase sales to a predominantly male readership, yet betray the preferred image of the women that were depicted. Secondly, it was established that vector analysis was a useful heuristic tool for establishing visual subjectivity in the visual representation of sportswomen.

\section{VERWYSINGS}

BISHOP, R. (2003). Missing in action: Feature coverage of women's sports in Sports Illustrated. Journal of Sport \& Social Issues, 27: 184-194.

BOUTILIER, M. \& SANGIOVANNI, L. (1983). The sporting woman. Champaign, IL: Human Kinetics.

COAKLEY, J.J. (2003). Sport in society. Issues and controversies. New York, NY: McGraw-Hill.

CROSS, J.L. (2006). Icons as ideology: A media construction. In I. Lassen, J. Strunck \& T. Vestergaard (Eds.). Mediating ideology in text and image: Ten critical studies (173-193). Amsterdam: John Benjamins.

DUNCAN, M.C. \& SAYAOVONG, A. (1990). Photographic images and gender in Sports Illustrated for Kids. Play \& Culture, 3(2): 91-116.

FAIRCLOUGH, N. (2001). "The dialectics of discourse". [www.ling.lancs.ac.uk/profiles/NormanFairclough]. Accessed 16 November 2009.

FAIRCLOUGH, N. (2003). Analysing discourse. Textual analysis for social research. London: Routledge.

FAIRCLOUGH, N. (2004). "Critical discourse analysis". [www.ling.lancs.ac.uk.staff/norman/paper5 .doc]. Accessed 18 December 2004. 
FINK, J.S. \& KENSICKI, L.J. (2002). "An imperceptible difference: Visual and contextual constructions of femininity in Sports Illustrated and Sports Illustrated Women". [www.leaonline.com]. Accessed 24 October 2006.

HARGREAVES, J. (1997). Women's sport, development, and cultural diversity: The South African experience. Women's International Forum, 20(2): 191-209.

HALLIDAY, M.A.K. (1994). An introduction to functional grammar. London: Edward Arnold.

HALLIDAY, M.A.K. \& MATHIESSEN, C. (2004). An introduction to functional grammar. London: Edward Arnold.

HOULIHAN, B. (2003). Sport and society. London: Sage.

KANE, M.J. (1996). "Media coverage of the post Title IX female athlete: A feminist analysis of sport, gender and power". [www.law.duke.edu/journals/djglp/homepage/djgv3a3.htm]. Accessed 4 November 2006.

KRESS, G. \& VAN LEEUWEN, T. (1996). Reading images: The grammar of visual design. London: Routledge.

KRESS, G. \& VAN LEEUWEN, T. (2006). Reading images: The grammar of visual design ( $2^{\text {nd }}$ ed.). London: Routledge.

MCGINNIS, L.; CHUN, S. \& MCQUILLAN, J. (2003). "A review of gendered consumption in sport and leisure. Academy of marketing science review". [http://www.amsreview.org]. Accessed 5 September 2004.

NASPERS. (2006). "Sirkulasiesyfers". [http://www.naspers.com/english/print.asp]. Accessed 24 October 2006.

OGLESBY, C.A. (1978). Women and sport: From myth to reality. Philadelphia, PA: Lea \& Febiger.

REID, L.N. \& SOLEY, L.C. (1979). "Sports Illustrated's coverage of women in sports. Journalism Quarterly, 56(4): 861-863. In M.C. Duncan, M.A. Messner \& L. Williams (Eds.). [www.la84foundation.org]. Accessed 13 November 2009.

SA SPORTS ILLUSTRATED (2004a.). Photobooth. Cape Town: Naspers, February issue.

SA SPORTS ILLUSTRATED (2004b). Photobooth. Cape Town: Naspers, March issue.

SA SPORTS ILLUSTRATED (2004c). Photobooth. Cape Town: Naspers, October issue.

SA SPORTS ILLUSTRATED (2006). Leading Off. Cape Town: Naspers, November issue.

SA SPORTS ILLUSTRATED (2008). Leading Off. Cape Town: Naspers, January issue.

SRSA (SPORT \& RECREATION SOUTH AFRICA) (2006). [www.srsa.gov.za]. Accessed 20 September 2006.

TITLE IX (1972). [www.justice.gov/crt/cor/coord/titleix.php]. Accessed 16 November 2009.

VAN DIJK, T.A. (1993). Discourse and society. London: Sage.

VAN DIJK, T.A. (1997a). The study of discourse. In T.A. Van Dijk (Ed.). Discourse as structure and process. Discourse studies: A multidisciplinary introduction (1-34). London: Sage.

VAN DIJK, T.A. (1997b). Discourse and interaction in society. In T.A. Van Dijk (Ed.). Discourse as social interaction. Discourse studies: A multidisciplinary introduction (1-37). London: Sage.

VAN DIJK, T.A. (2004). "Ideology and discourse analysis". [www.discourse-in-society.org]. Accessed 12 April 2006.

VAN DIJK, T.A. (2005). Contextual knowledge management in discourse production: A CDA perspective. In R. Wodak \& P. Chilton (Eds.). A new agenda in critical discourse analysis (87-97). Philadelphia, PA: John Benjamins. 
WODAK, R. (2006). Images and news in a globalised world: Introductory thoughts. In I. Lassen, J. Strunck \& T. Vestergaard (Eds.). Mediating ideology in text and image: Ten critical studies (1-18). Philadelphia, PA: John Benjamins.

WODAK, R. \& MEYER, M. (2001). Methods of critical discourse analysis. London: Sage.

WOMEN'S SPORTS FOUNDATION (2010). "Mixed media: Images of female athletes. Female athletes remain distastefully on display despite efforts by marketing campaigns to redefine the female image". [www.womenssportsfoundation.org]. Accessed 7 April 2010.

Prof. Adelia Carstens: Departement Geesteswetenskaplike Opvoedkunde, Fakulteit Opvoedkunde Universiteit van Pretoria, Pretoria, Republiek van Suid-Afrika. Tel.: +27 (0)12 4205547, Faks: +27 (0)12 4205637. Epos-adres: adelia.carstens@up.ac.za 